\title{
COTIDIANO E TRABALHO: CONCEPCCÕES DE INDIVÍDUOS PORTADORES DE INSUFICIÊNCIA RENAL CŔÔNICA E SEUS FAMILIARES ${ }^{1}$
}

Carreira L, Marcon SS. Cotidiano e trabalho: concepções de indivíduos portadores de insuficiência renal crônica e seus familiares. Rev Latino-am Enfermagem 2003 novembro-dezembro; 11(6):823-31.

Este é um estudo descritivo-exploratório, que objetivou conhecer as concepções, atitudes e comportamentos relacionados ao trabalho, de 16 indivíduos portadores de insuficiência renal crônica (IRC) e seus familiares. Os dados foram coletados no período de abril a agosto de 2000, por meio de entrevista semi-estruturada. Os resultados revelaram que 0 trabalho é valorizado por todas as famílias como fonte de saúde e de provimento financeiro, além de ser importante na formação do caráter do indivíduo; e que a maioria dos indivíduos com IRC não desenvolvem atividade remunerada, e, quando o fazem, contam com a ajuda e compreensão do patrão e familiares. Conclui-se que IRC e seu tratamento não constituem impedimento direto e absoluto à realização desse tipo de atividade, mas trazem limitações importantes. Considera-se necessário os profissionais de saúde se aliarem na busca de apoio por parte de familiares e sociedade, para que esses indivíduos possam ser inseridos no mercado de trabalho quando o desejarem e tiverem condições para tal.

DESCRITORES: trabalho; insuficiência renal crônica; família

\section{DAILY LIFE AND WORK: CONCEPTIONS OF CHRONIC RENAL INSUFFICIENCY (CRI) PATIENTS AND THEIR RELATIVES}

This descriptive and exploratory research aimed to know the conceptions, attitudes and behaviors about work as reported by 16 chronic renal insufficiency patients and their relatives. Data were collected from April to August 2000 through semi-structured interviews. The results revealed that work is valued by all families as a source of health and financial resources, besides being important for individuals' character formation; that most CRI patients do not carry out any remunerated activities and, when they do, they count on the help and understanding of the boss and relatives. We conclude that CRI and its treatment do not directly or absolutely impede the realization of this kind of activity, but entail important limitations. We consider it is necessary for health professionals to join in the search for support by relatives and society, so that these people can be inserted in the labor market when they want to and are in the right conditions.

DESCRIPTORS: work; chronic renal insufficiency; family

\section{COTIDIANO Y TRABAJ O: CONCEPCIONES DE INDIVIDUOS PORTADORES DE INSUFICIENCIA RENAL CRÓNICA Y SUS FAMILIARES}

Estudio descriptivo y exploratorio que se propuso conocer las concepciones, actitudes, creencias y comportamientos de 16 individuos portadores de insuficiencia renal crónica (IRC) y sus familiares, en relación con el trabajo. Los datos fueron recogidos entre abril y agosto del 2000, a través de una entrevista semi-estructurada. Los resultados revelaron que el trabajo es valorizado por todas las familias como fuente de salud y de provisión financiera, además de ser importante en la formación del carácter del individuo. Igualmente, la investigación mostró que la mayoría de los individuos con IRC no desarrollan una actividad remunerada y cuando lo hacen, cuentan con la ayuda y la comprensión del patrón y de los familiares. Concluimos, por tanto, que la IRC y su tratamiento no constituyen un impedimento directo para la realización de este tipo de actividad, pero que trae limitaciones importantes. Consideramos que los profesionales de la salud se deben unir para buscar apoyo en familiares y en la sociedad en general para que estos individuos puedan ser inseridos en el mercado de trabajo cuando lo deseen y tengan condiciones para ello.

DESCRIPTORES: trabajo; insuficiencia renal crónica; familia

\footnotetext{
${ }^{1}$ Extraído da Monografia apresentada ao Curso de Especialização em Enfermagem do Trabalho na Universidade Estadual de Maringá; 2 Enfermeira especialista em Enfermagem do Trabalho, Mestranda da Escola de Enfermagem Anna Nery da Universidade Federal do Rio de Janeiro, inserida no Núcleo de Pesquisa de Fundamentos do Cuidado de Enfermagem (Nuclearte); ${ }^{3}$ Enfermeira, Doutor em Filosofia da Enfermagem, Professor da Universidade Estadual de Maringá, Pesquisador do CNPq e coordenadora do Núcleo de estudos, pesquisa, assistência e apoio à família, e-mail: ssmarcon@uem.br
} 
INTRODUÇÃO

$\boldsymbol{A}$ concepção de que o processo saúde-doença ultrapassa o aspecto biológico e envolve todo o contexto social, político e cultural do indivíduo, incluindo sua família, acompanha-nos desde o período da graduação, de forma que, quando tivemos oportunidade, em nosso primeiro emprego, de conviver com alguns indivíduos portadores de insuficiência renal crônica (IRC), submetidos a tratamento dialítico, passamos a perceber, de forma mais clara, aspectos importantes das condições de vida dessa população e a constatar a amplitude das questões direta ou indiretamente vinculadas à manutenção da qualidade de vida para o ser humano.

A partir de então, passamos a valorizar, ainda mais, o conceito de qualidade de vida, sob um enfoque multidimensional, enquanto construção subjetiva e composta por elementos positivos e negativos ${ }^{(1)}$, os quais envolvem as condições de saúde física, o repouso, as funções cognitivas, a satisfação sexual, o comunicar-se, o alimentar-se, a reserva energética, a presença/ausência de dor, o comportamento emocional, o lazer, a vida familiar e social e, de forma particular, o trabalho(2).

O trabalho sempre esteve presente nas atividades do ser humano, desde seus primeiros agrupamentos sociais, nos primórdios da civilização. O Homo sapiens, por exemplo, só se diferenciou dos outros primatas quando começou a transformar seu meio por meio de uma atividade física e lúdica, que hoje denominamos trabalho ${ }^{(3)}$.

A obra "O Trabalho em Migalhas"(4), revela-nos que é pelo trabalho que o homem, ajudado por instrumentos, modifica seu próprio meio e, em contrapartida, pode modificar-se a si próprio. Ademais, da mesma forma que o trabalho pode significar a etiologia de uma patologia no homem, também constitui o seu processo de viver e a ele é inerente. A atividade laboral, portanto, tem papel determinante no equilíbrio psicológico do ser humano, à medida que o mantém solidamente vinculado à realidade, levando-nos a perceber quão complexas são as relações entre o indivíduo e o trabalho, constituindo, muitas vezes, fator norteador da vida humana, com implicações diretas nas condições fisiológicas, psíquicas, mentais e sociais do indivíduo.

Para Freud, o trabalho, por si próprio e pelas relações humanas que implica, oferece a oportunidade de uma descarga aos impulsos da libido ${ }^{(4)}$, além de proporcionar ao indivíduo os meios necessários para sua subsistência e, assim, justificar sua existência na sociedade. Sociologicamente, é por meio do trabalho que nos socializamos, coletivizamos, convivemos ${ }^{(4)}$.

Assim sendo, percebemos que o trabalho, além de representar uma espécie de vínculo do indivíduo à comunidade humana, conforme afirma Freud, também constitui uma das formas mais ativas de os indivíduos conviverem melhor no meio familiar, sem o qual eles perdem o equilíbrio, desagregam-se.

Compreendendo, então, a importância do trabalho para os seres humanos, é que refletimos sobre os indivíduos portadores de IRC que estão em tratamento dialítico, considerando as implicações que essa doença e seu tratamento podem trazer no cotidiano e, conseqüentemente, no exercício do trabalho, tanto por parte dos pacientes quanto de seus familiares.

Os dados estatísticos revelam que, no Brasil, há cerca de 20.000 pacientes em hemodiálise, com uma incidência anual em torno de 100 casos novos por milhão de habitantes, embora apenas 60 pacientes novos iniciem tratamento dialítico, por falta de diagnóstico ou por tratamento incorreto ${ }^{(5)}$.

A pessoa que vivencia um desequilíbrio em seu estado de saúde, como a IRC, vê-se constantemente em perigo de perder sua integridade tanto física como psíquica, ou seu lugar na família e na sociedade, em decorrência das alterações em suas funções orgânicas ${ }^{(6)}$. A família, por sua vez, também sofre um processo de desajuste em sua forma de organização e em suas funções, pois passa a ter que adaptar a dinâmica familiar às necessidades $e$ atividades relativas ao tratamento e apoio ao membro portador da deficiência ${ }^{(6)}$.

No caso específico das famílias de indivíduos portadores de IRC, constatamos que as necessidades de adaptação da dinâmica familiar são intensas e tendem a aumentar na medida em que há evolução da doença, porquanto o paciente passa a apresentar dificuldades físicas que o impedem de assumir, de forma autônoma, seus compromissos, inclusive os relacionados ao tratamento, o que exige o compromisso e dedicação da família, manifestada de diversas formas e em diferentes situações ${ }^{(7-8)}$. Um exemplo dessas manifestações é o fato de ser relativamente comum a presença de um cuidador familiar nas sessões de hemodiálise, especialmente em seu início e no fim, quando eles levam e buscam o familiar para o tratamento.

Assim, considerando a grande incidência da IRC 
no Brasil, as alterações no cotidiano dos portadores dessa doença, decorrentes do tratamento dialítico, o grau de envolvimento de seus familiares no tratamento, bem como a importância do trabalho na vida das pessoas, é que nos propusemos a desenvolver esta investigação, tendo, como objetivo, conhecer as concepções, atitudes e comportamentos de indivíduos portadores de IRC, submetidos a tratamento dialítico e seus familiares, relacionados ao trabalho.

Ao conhecer como o indivíduo e seus familiares percebem e lidam com as questões do cotidiano que os preocupam, o profissional pode planejar e implementar uma assistência mais individualizada e integralizada. Consideramos ser de extrema importância que os profissionais de saúde atentem, também, para a questão do trabalho na vida de indivíduos portadores de IRC, pois esta é uma das facetas das necessidades experienciadas por eles, em virtude não só dos aspectos financeiros relacionados à ausência de trabalho remunerado, mas, principalmente, de toda a problemática envolvida, como, por exemplo, a presença de ociosidade, o sentimento de inutilidade e desvalorização, assim como a sensação de ser um peso/fardo para a família.

\section{ASPECTOS METODOLÓGICOS}

Trata-se de um estudo descritivo-exploratório, que adotou os pressupostos do método qualiquantitativo, no que concerne a seu esquema interpretativo, e foi realizado na cidade de Maringá-PR, junto a 16 famílias de indivíduos adultos portadores de IRC e submetidos a tratamento na Unidade de Diálise de um hospital geral.

Os dados foram coletados no período de abril a agosto de 2000, utilizando-se, como técnica, a entrevista semi-estruturada. As entrevistas foram agendadas previamente e realizadas no domicílio dos pacientes, e tiveram uma duração média de cinqüenta minutos. Nessa ocasião, as respostas dos informantes foram registradas manual e integralmente e, como forma de validação, elas foram lidas para os informantes, que concordavam com a transcrição de seu conteúdo ou as complementavam e/ ou corrigiam, quando achavam necessário.

Os informantes foram, na maioria das vezes, os pacientes, juntamente com outros membros da família que estavam no domicílio na hora da entrevista, o que deu a ela um caráter coletivo, uma vez que outros membros da família tiveram oportunidade de relatar sua experiência atual e pregressa com o trabalho, ou mesmo de manifestar sua opinião, seja complementando, seja discordando de alguma informação prestada pelo paciente. Somente em dois casos não ocorreu a participação ativa do paciente na coleta de dados. Nestes, os informantes foram outros membros da família - filha, no caso do paciente com seqüela de AVC, e esposa, no caso de paciente tímido, que deixou a mulher ir tomando a frente de tudo. Nesses momentos, tomamos o cuidado de solicitar a presença do paciente durante a entrevista, por entendermos que, assim, estaríamos valorizando sua pessoa e sua participação.

O instrumento utilizado na coleta de dados, um roteiro semi-estruturado, foi elaborado pelas próprias autoras, com base nos objetivos do estudo. Posteriormente, ele foi submetido à validação aparente $e$ de conteúdo por quatro professores do Departamento de Enfermagem da Universidade Estadual de Maringá. Todas as sugestões apresentadas, que incluíam, além de maior detalhamento ou mudança na linguagem utilizada, também a exclusão e inclusão de itens, foram acatadas integralmente, ficando o instrumento, em sua forma definitiva, constituído de dezoito questões.

A realização do estudo obedeceu aos preceitos da Resolução 196/96 do Conselho Nacional de Saúde ${ }^{(9)}$, ou seja, esta só foi autorizada pelos proprietários do serviço de saúde após aprovação do Comitê de Ética da instituição signatária do estudo, e iniciada após a obtenção do consentimento livre e esclarecido dos participantes. Quando da solicitação de participação no estudo, foram informados os seus objetivos, tipo de participação desejada, direito à livre opção em participar ou não da pesquisa, assim como a desistir de participar em qualquer momento em que o desejassem. Ademais, foi garantido total desvinculamento entre participação no estudo e a assistência prestada pela Unidade de Diálise, e anonimato de todas as informações prestadas quando da divulgação dos resultados do estudo. Por fim, comprometemo-nos a deixar uma cópia da versão final do trabalho na Unidade de Diálise, para que todos tivessem acesso a ela.

Os dados foram analisados por meio do emprego da estatística descritiva, porém com maior ênfase no conteúdo das falas, numa tentativa de identificar e categorizar aspectos relevantes da experiência e vivência apontadas pelos pacientes e seus familiares. 
APRESENTAÇÃO E ANÁLISE DOS DADOS

Caracterização dos pacientes em estudo e suas famílias

A maioria dos doentes é casada ( $75,0 \%)$, do sexo feminino $(68,8 \%)$, e encontra-se em uma faixa etária produtiva da vida, ou seja, dez (62,5\%) têm menos de sessenta anos de idade, cinco dos quais menos de quarenta anos. Essas características são coerentes com a posição familiar, já que nove mulheres (56,3\%) estão na situação de mãe e/ou esposa, quatro homens $(25,0 \%)$ são pais e/ou esposos e apenas três indivíduos (18,7\%) estão na condição de filhos.

Quanto ao nível de escolaridade, constatamos que $12,5 \%$ são analfabetos, 31,2\% não estudaram além da quarta série do ensino fundamental; $18,7 \%$ não chegaram a esse nível de ensino; $12,5 \%$ completaram o ensino médio e somente quatro $(25,0 \%)$ iniciaram um curso de nível superior, dos quais apenas um o completou.

No que diz respeito às famílias, a maioria delas $(81,3 \%)$ é do tipo nuclear, ou seja, formada pelo casal pai e mãe - e filhos ${ }^{(10)}$-, constituídas de duas a quatro pessoas (75\%). Quanto à escolaridade, 62,5\% dos genitores não completaram o ensino fundamental, sendo que, em apenas duas das famílias (12,5\%), um deles iniciou um curso de nível superior.

No que se refere à etapa de desenvolvimento ${ }^{(11)}$, constatamos que quatro famílias estão no estágio da velhice, uma na meia-idade, quatro em fase de lançamento, duas na fase dos filhos adolescentes e duas na fase dos filhos em idade escolar. Ademais, outras três famílias, em função de conviverem, diuturnamente, duas e até três gerações, vivenciam mais de uma fase, principalmente pela presença de um neto em idade escolar ou pré-escolar.

Em 75\% das famílias, outros membros, além do indivíduo portador da IRC, relatam alguma doença crônica, como diabetes mellitus, hipertensão arterial, doença cardíaca, doença mental, entre outras. É interessante ressaltar que, normalmente, os outros membros da família que apresentam problemas de saúde ocupam a posição de esposo/esposa ou mãe do indivíduo portador de IRC, o que nos leva a indagar se isso não seria um reflexo da sobrecarga decorrente da responsabilidade em ser o cuidador familiar, já que o exercício dessa função pode provocar desgaste físico e mental, desencadeando desequilíbrio de determinados órgãos ou sistemas ${ }^{(12)}$.
Também chamou nossa atenção o fato de, em três das cinco famílias nas quais existiam crianças, estas apresentarem problema de saúde crônico, mais especificamente a bronquite, o que também pode estar relacionado com seu estado emocional.

Esses dados confirmam o que tem sido identificado em estudos realizados por integrantes do Nepaaf (Núcleo de estudo, pesquisa, assistência e apoio à família): a existência de uma fragilidade na saúde de familiares de doentes crônicos, havendo, portanto, uma maior probabilidade de surgimento de doenças em outros membros da família, inclusive nas crianças ${ }^{(13)}$.

O desemprego, por sua vez, não foi referido como um problema vivenciado pelas famílias, provavelmente em função da etapa de seu desenvolvimento, de boa parte dos doentes já estarem aposentados (37,5\%) e, também, do fato de que as mulheres constituem a maior parte dos doentes $(68,7 \%)$, e uma parcela delas, antes mesmo do aparecimento da doença, já desenvolvia atividades apenas no lar (36,4\%) ou já era aposentada (18,2\%).

A maioria das famílias, no entanto, queixou-se da baixa remuneração recebida por seus membros, o que atribuíam ao tipo de atividade que estes executam - serviço em fábrica ou indústria, de vendedor ambulante, de empregada doméstica, entre outras, além da baixa remuneração recebida pelos aposentados em nosso país.

O trabalho no cotidiano de vida de portadores de insuficiência renal crônica

Quando investigamos as atividades que os indivíduos portadores de IRC desenvolviam antes do desenvolvimento da doença, verificamos que apenas duas mulheres (12,5\%) já estavam aposentadas e referiram que auxiliavam nos afazeres domésticos, quatro $(25,0 \%)$ realizavam apenas atividades domésticas, e os demais $(62,5 \%)$ realizavam algum tipo de trabalho remunerado. Após o início da doença, no entanto, quatro se aposentaram, três dos quais exclusivamente em decorrência da doença, já que dois tinham em torno de 40 anos, e outro, 57 anos; dois estavam afastados do trabalho temporariamente, e duas pessoas deixaram de trabalhar, sem, no entanto, conseguir aposentadoria. Uma delas, que possui menos de 21 anos, continuava estudando. Somente duas pessoas (12,5\%) ainda desenvolviam algum tipo de trabalho remunerado, das quais uma se ocupava de atividade autônoma e outra tinha a cooperação do 
empregador, liberando-o para a realização do tratamento dialítico.

A comparação da atividade laboral desenvolvida pelos indivíduos que têm IRC antes do início da doença com aquela desenvolvida depois revela que a maioria $(75 \%)$ experimentou mudanças, sendo que oito deles deixaram totalmente de desenvolver qualquer tipo de trabalho remunerado, em decorrência das limitações que a doença e o tratamento Ihes impôs. Dos quatro pacientes que referiram não ter experienciado mudança na vida laboral, três desenvolviam apenas serviços domésticos e apenas um trabalhava como empregado em empresa privada. Seus relatos, no entanto, nos permitem identificar que, mesmo para eles, fizeram-se necessários alguns tipos de adaptação, e mesmo colaboração de familiares e/ou empregadores.

Consideramos que a atividade laboral no cotidiano dos portadores de IRC e, conseqüentemente, no de sua família, é uma questão muito importante a ser observada e abordada pelos profissionais de saúde, já que essa doença se manifesta em diversas faixas etárias, em especial na fase produtiva da vida das pessoas. Um exemplo disso é a população deste estudo: $75 \%$ apresentaram a sintomatologia da doença renal - com o conseqüente início do tratamento - em fase produtiva da vida, cinco delas $(41,6 \%)$ tinham menos de trinta anos.

Cabe destacar que, dentre os dezesseis pacientes, apenas um não apresentava condições de desenvolver qualquer tipo de atividade laboral, em decorrência de seqüela de Acidente Vascular Cerebral (AVC).

Concepções e comportamentos relacionados ao trabalho

Entendemos que as concepções dos indivíduos sobre determinados aspectos da vida podem estar demonstradas ou implícitas em atitudes e comportamentos presentes nas relações familiares, o que nos levou a investigar as percepções sobre o significado do trabalho na vida das pessoas, bem como o inicio dessa atividade para os membros da família.

Constatamos que para a maioria das famílias (62,5\%), o trabalho é compreendido como uma forma de realização e valorização pessoal na sociedade em que vivemos. Sete famílias (43,7\%) apontaram que o trabalho constitui o referencial de nossas vidas, e, sendo assim, o que norteia os planos que fazemos em relação à nossa convivência familiar e social, às conquistas e lazeres. Para outras seis famílias (37,5\%), o trabalho representa a fonte de renda financeira da família, na qual se fundamenta todo o sustento das necessidades básicas do homem. Outros significados mencionados com menor freqüência foram: utilidade social e familiar (18,7\%), saúde física e mental $(12,5 \%)$ e independência para gerenciar a vida, gastos e necessidades (12,5\%): É muito importante poder dar conta do serviço, ser útil, sem contar que assim as coisas saem como a gente gosta. ( $F$ 1) O trabalho traz satisfação, significa saúde, disposição, diversão. (F 2); O trabalho é tudo para o homem, é a satisfação pessoal, é o pão de todos os dias, é também a dignidade. (F 3)

Para identificar o comportamento e atitude em relação ao trabalho, investigamos como foi o início da atividade laboral para os portadores de IRC e como as famílias vêem a participação dos filhos na realização das tarefas domésticas e a época em que a criança deva ser envolvida com atividade remunerada.

As manifestações apresentadas permitiram-nos identificar que grande parte dos portadores de IRC (nove: $56,3 \%$ ) começaram a desenvolver um trabalho remunerado entre os dez e dezesseis anos de idade, três (18,8\%) começaram antes de completar dez anos, e quatro (25\%) só após os vinte anos. Porém, quando se trata de seus filhos, observamos que o início desse tipo de trabalho foi um pouco mais tardio, já que, em $53,8 \%$ das famílias, seus filhos iniciaram algum tipo de atividade remunerada entre os doze e os dezessete anos. Em uma, foi antes dos dez anos, e, em duas, após os vinte e um anos. Quatro famílias que possuem filhos com idade entre cinco e dezessete anos afirmaram que estes ainda não trabalham.

Esses dados vão ao encontro das opiniões mencionadas pelas famílias sobre o trabalho infantil, pois metade delas demonstraram ser favoráveis ao trabalho de crianças, justificando que isso faz que haja ocupação do seu tempo, evitando, assim, o envolvimento na marginalidade, ao mesmo tempo em que as crianças vão aprendendo a ter prazer e a valorizar o trabalho. ... já pode começar a trabalhar sim, porque, assim, não sobra tempo para a marginalidade, como que com essa idade tem muita gente que rouba e faz um monte de coisa que não deve... (F 1)

Porém, os outros $50 \%$ das famílias acreditam que o trabalho, no período da infância e adolescência, interfere de forma negativa na formação da personalidade da pessoa, além de não permitir um bom preparo para a vida adulta, pois entendem que essa fase é de estudo e preparo profissional. ... esta fase é de estudo, de preparo...(F 3).... O trabalho 
atrapalha a formação dela, não concordo, elas não têm tempo de brincar, de fazer as coisas que uma criança faz. Cria revolta na pessoa... (F 13).

Quanto ao desenvolvimento de atividades domésticas, a totalidade das famílias afirmou acreditar ser importante que todos colaborem nesse tipo de trabalho, iniciando-as, em sua maioria, já no início da adolescência (dez a doze anos), por entenderem que esta é uma forma de aprender a dar conta das necessidades da vida. ... Em casa tem a obrigação de ajudar, porque aprendem a se virar sozinhos quando precisar... (F 15).

Apesar disso, em duas famílias, os filhos não colaboram na realização de nenhum tipo de trabalho doméstico, e, em outras duas, somente os do sexo feminino o desenvolvem, provavelmente por entenderem que esse tipo de trabalho é de responsabilidade da mulher, tal como tem sido identificado em alguns estudos realizados com pessoas de mais idade ${ }^{(14)}$ ou em determinadas culturas $^{(15)}$.

\section{Alterações decorrentes da doença e seu tratamento}

A presença de uma doença crônica no ambiente familiar exige uma série de alterações na estrutura familiar, de forma que a família possa adaptar-se para conviver com as novas necessidades decorrentes do problema de saúde. Ademais, as mudanças decorrentes da presença da IRC e de seu tratamento não atingem apenas o doente, mas todas as pessoas que compõem sua rede social ${ }^{(16)}$. Grande parte das famílias (nove) apontou mudanças no ritmo de vida que tinham, inclusive no que se refere ao trabalho. Enfatizaram que essas alterações provocaram uma situação muito difícil para a família, pois houve mudança na rotina de vida do indivíduo, e, como conseqüência, na da família também, desde o tipo de alimentação utilizado, até a quantidade e tipo de programas de lazer.

É interessante observar que, enquanto o paciente faz referência às restrições alimentares impostas pela doença e seu tratamento, os outros membros familiares, de modo geral, enfatizam outro aspecto para essa mesma restrição - o financeiro -, visto que a limitação desses recursos, decorrente da diminuição na renda familiar, implica diretamente o acesso a bens de consumo: Ficou bem difícil, porque agora não dá mais para passear, nem tudo pode comer, tem horário do remédio, e ainda tem noite que não passo bem...(F 2). Mudou muito a estrutura da família, os dois deixaram de trabalhar e passaram a viver só do salário da filha... (F 3).

A condição socioeconômica e cultural, por sua vez, interfere na qualidade da aderência do paciente ao tratamento, especialmente quanto à alimentação, sendo relativamente comum o fato de paciente diabético, por exemplo, apesar das restrições existentes, continuar se alimentando basicamente com carboidratos, que é mais acessível economicamente.

Ao mencionarem os tipos de mudanças ocorridos na vida familiar, os informantes deram maior ênfase às questões que consideram mais significativas em seu cotidiano, de forma que cinco famílias (35,7\%) apontaram a diminuição de passeios e atividades de lazer, decorrentes tanto da regularidade nos horários de medicação e das especificidades do tratamento como da diminuição na renda familiar; quatro famílias (28,6\%) deram maior ênfase ao aspecto financeiro, referindo que, somado à diminuição na renda familiar, ainda houve aumento de gastos com medicamentos e alimentação especial, entre outras despesas. O desgaste emocional dos familiares foi demonstrado por quatro famílias $(28,6 \%)$ por meio da verbalização de maior preocupação com a vida e saúde das pessoas, em especial do indivíduo portador de IRC, os quais, além disso, fizeram referência ao fato de que o tratamento da doença renal exige muita responsabilidade e participação dos familiares. Uma das famílias relatou ter havido uma mudança total em sua vida, visto ter sido necessário mudar de cidade para ficar mais próximo do local onde o tratamento é realizado.

A família de Priscila, por sua vez, ressaltou o aspecto positivo das alterações ocorridas no seio familiar, representado por maior união entre seus membros: A doença despertou um sentimento de ajuda e cumplicidade entre nós da família, o que não achava que existia. ( $F 7$ )

O tempo gasto com o tratamento é uma realidade para esses pacientes e seus familiares. No caso da hemodiálise, são necessárias, em média, de 2 a 3 sessões por semana, com duração de quatro horas cada; enquanto no CAPD - técnica de diálise peritoneal realizada no domicílio - são quatro trocas manuais por dia, com duração média de quarenta e cinco minutos cada uma ${ }^{(17)}$.

Nos dois casos, a observância rigorosa dos horários/dias previamente determinados constitui condição importante para a eficácia do tratamento. Assim sendo, a família desempenha papel importante, seja acompanhando o paciente às sessões de hemodiálise, seja realizando a troca das bolsas de diálise no domicílio. É por essa razão 
que a existência de um indivíduo com IRC na família interfere tanto em sua dinâmica.

Preocupadas com essa questão, investigamos, junto aos indivíduos, como era gasto o seu tempo e averiguamos que nove deles (56,3\%), apesar de o tratamento ocupar muitas horas de suas vidas, ainda conseguem ocupar parte de seu tempo com alguma forma de trabalho, como, por exemplo, o desenvolvimento do serviço doméstico; os demais, no entanto, referiram que vivem para o tratamento da doença, reforçando o que já tem sido identificado em outros estudos, quando se constata que os indivíduos submetidos a hemodiálise têm pouquíssimas atividades significativas fora do tratamento ${ }^{(18)}$. A possibilidade de poder continuar contribuindo para o andamento das atividades da vida em família é muito importante, pois, "Apreciar a sua produção após um trabalho desenvolvido é salutar para qualquer indivíduo, bem como traz sensações de ser capaz, de prazer, enfim de estar vivo. E essas sensações é que fazem com que o ser adquira forças e estímulo para prosseguir rumo a novos produtos, em busca de atingir um nível de satisfação adequado"(19).

Quanto aos sentimentos desses indivíduos em relação à sua forma de vida (enfatizem-se aqui as questões referentes ao trabalho nesse processo de viver, influenciando e sendo influenciado pela presença da doença renal e seu tratamento), constatamos que seis $(37,5 \%)$ experimentam sentimentos de dependência de outras pessoas e do tratamento, traduzida pela falta de liberdade para realizar as atividades de que gostam, e para viverem com uma certa autonomia de ir e vir: ... a gente dá trabalho para todo mundo da família, fica na dependência do tratamento para viver. $(F$ 16); ...me sinto presa, sem liberdade...(F 10)

Alguns $(31,3 \%)$ revelaram sentimentos de conformação, ao tentarem entender que a única forma de sobrevivência é o tratamento dialítico, o que exige adaptação à nova realidade: ... é muito difícil aceitar, mas não adianta ficar reclamando, tem que fazer o tratamento e pronto.(F 4); ...eu me conformei com a situação, a gente se acostuma...(F 13). É importante salientar que a postura de conformismo, no entanto, não representa necessariamente uma aceitação da doença, mas, sim, do tratamento, visto que este representa a única possibilidade de continuar sendo no mundo, existindo ${ }^{(20)}$.

Outros sentimentos revelados foram o de revolta (18,75\%), frustração em relação à limitação para o trabalho, perda do sentido de viver e insegurança, por pensar no limiar entre a vida e a morte: ...fico muito nervoso de ficar parado, sem trabalhar... (F 2); ...fico muito deprimida e insegura, não saber até quando vou viver... ( $F 14) ;$...sem poder trabalhar como antes, perdeu o brilho de viver...(F 15). Ressalte-se que os indivíduos participantes do estudo, ao expressarem seus sentimentos, demonstram, mais uma vez, a importância do trabalho na saúde e na vida das pessoas e suas famílias, em especial daqueles portadores de IRC, já que a presença da doença no seio familiar traz alterações em sua rotina de vida e de trabalho, desencadeando sentimentos que apontam para desgaste da saúde mental da família.

Ademais, não podemos deixar de considerar que a forma como as pessoas reagirão frente aos seus problemas e os mecanismos dos quais se utilizarão para enfrentá-los, estão relacionados às suas crenças e valores e ao apoio que recebem de seus entes queridos ${ }^{(16)}$.

É importante destacar que, apesar da presença de revolta, de descrença no tratamento e conformação, os indivíduos portadores de IRC não podem abandonar a luta e a busca por uma melhor qualidade de vida, mesmo que a superação/eliminação de sinais e sintomas reveladores de debilidades do corpo ou da mente não seja possível. As pessoas, portanto, precisam ser consideradas nos estados que elas podem se apresentar, sem exigirIhes qualquer sacrifício eugênico de tornarem-se sadias para efeitos estatísticos ${ }^{(21)}$.

Expectativas de vida de indivíduos renais crônicos

Uma outra questão abordada foi a expectativa de vida; e os resultados obtidos reforçam novamente a importância do trabalho na vida das pessoas, visto que esses resultados nos permitiram constatar que essas expectativas, em sua maioria, estão diretamente relacionadas à possibilidade de um transplante renal, para que uma nova etapa da vida se inicie e surjam melhores perspectivas de trabalho e lazer. Fazer um transplante e voltar a trabalhar com costura, que é o que eu gosto. (F 5, 11 e 15)

Não obstante, um número significativo de pacientes e familiares $(25,0 \%)$ demonstrou não ter nenhuma expectativa de vida, embora apenas um dos pacientes apresentasse limitações físicas definitivas, além de que, somando-se a esse fato, ele já tinha 78 anos de idade. Não tenho expectativas na minha vida. Já criei os filhos e é isso. (F 4)

Entendemos que a expectativa de vida no ser 
humano é um fator de grande importância a ser considerado em praticamente todas as circunstâncias, porque a sua presença, também, estará influenciando o comportamento do indivíduo perante a vida, e, conseqüentemente, perante as questões que envolvem a saúde e a doença.

\section{CONSIDERAÇÕES FINAIS}

Durante o desenvolvimento deste estudo, constatamos a escassez de pesquisas que valorizem a perspectiva do indivíduo com IRC e seus familiares, especialmente no que se refere à questão do trabalho. No entanto, os dados deste estudo revelam a predominância de indivíduos que desenvolveram a doença ainda na fase produtiva da vida, demonstrando a relevância de analisarmos o objeto deste estudo, especialmente quando consideramos a sociedade capitalista/consumista em que vivemos e o fato de a maioria das pessoas portadoras de IRC, presentes neste estudo, serem casadas e estarem na posição familiar de pais e cônjuges, o que os remete diretamente à questão do trabalho, haja vista suas responsabilidades, inclusive financeiras, com seu lar e com as condições da vida em família.

O trabalho na vida das pessoas e também do indivíduo renal crônico é muito importante. Pacientes e seus familiares apontaram que ele constitui o referencial de tudo na vida, condição essencial para a realização e a valorização pessoal, fazendo parte, inclusive, da formação educacional da criança e do caráter do indivíduo, mesmo quando realizado apenas no âmbito doméstico.

Assim, apesar de havermos identificado que apenas dois indivíduos mantinham algum tipo de vínculo empregatício, constatamos que, de forma geral, a doença renal e seu tratamento não constituem fator impeditivo direto e absoluto para a realização de algum tipo de atividade remunerada por parte da maioria dos doentes. Não obstante, precisamos reconhecer as limitações e conseqüências do tratamento dialítico, já que os resultados deste estudo revelam quanto os mesmos interferem na dinâmica e na relação familiar, na rotina de vida e no lazer desses indivíduos e de suas famílias.

Em que pese isso, precisamos lutar para que a necessidade de realizar o tratamento, quando o indivíduo tem vontade e condições para isso, não constitua empecilho direto para o desenvolvimento de diversas atividades, incluindo o trabalho, visto que a impossibilidade de trabalhar representa uma condição de risco para saúde mental do ser humano, especialmente quando envolve limitação física e preconceito.

Ademais, diante do atual panorama na saúde brasileira, representada pelo aumento na incidência de doenças crônicas, e da conscientização de que a ausência da possibilidade de trabalho constitui uma necessidade humana básica afetada, nós, profissionais da saúde, precisamos entender que faz parte de nosso trabalho e do nosso compromisso social trabalharmos em prol de uma nova mentalidade social. Assim, esforços devem ser envidados no sentido de tentar amenizar essa problemática, favorecendo e incentivando a reintegração na sociedade, não apenas do doente renal, mas de todos os portadores de doença crônica.

Para tanto, fazem-se necessárias adaptações e a colaboração por parte dos familiares e, principalmente, da sociedade, de forma que esses indivíduos possam ser inseridos no mercado de trabalho, possibilidade esta ainda bastante restrita no país. Contudo, apesar das limitações existentes, é preciso que se invista na busca de soluções para essa problemática, favorecendo, assim, a oportunidade de uma existência mais digna para todos.

Cabe destacar o fato de havermos constatado que as expectativas de vida, especialmente em relação ao trabalho, estão diretamente relacionadas à possibilidade da realização de um transplante renal. Assim sendo, cabe a nós, profissionais e pesquisadores da área da saúde, buscarmos, cada vez mais, estratégias que possam favorecer e ampliar as perspectivas de sua realização, pois esse tipo de tratamento pode implicar melhores condições de vida. Resta-nos, portanto, o compromisso, o engajamento e a responsabilidade pela realização de campanhas junto à sociedade em geral, para conscientização sobre a importância da doação de órgãos.

Consideramos, ainda, que os dados deste estudo apontam um papel preponderante para os profissionais da saúde junto à população de risco, por meio de ações que possam retardar as manifestações da doença e, mesmo depois de doente, ajudando o paciente a desenvolver uma auto-imagem positiva, a descobrir maneiras novas de viver dentro de seus limites e a desenvolver um estilo de vida que lhe permita assumir a responsabilidade por seu tratamento e sua vida, enfim, ser um indivíduo ativo na sociedade em que vive. 


\section{REFERÊNCIAS BIBLIOGRÁFICAS}

1. Minayo MCS, Hartz ZMA, Buss PM. Qualidade de vida e saúde: um debate necessário. Ciência e Saúde Coletiva 2000; 5(1):7-18.

2. Silva MAD. A importância da manutenção da qualidade de vida. Rev Soc Cardiol Estado São Paulo 1996 set/out; 6(5):657-60.

3. Marx K. O capital. Edição condensada. Rio de Janeiro (RJ): Melso; 1961.

4. Friedmann G. O trabalho em Migalhas. São Paulo (SP): Perspectiva; 1972.

5. Bienart JC. Sobrevida em Hemodiálise. In: CRUZ J. Atualidade em nefrologia, 3. São Paulo (SP): Savier; 1994. p.155-60.

6. Ciconelli MIRO. O paciente com insuficiência renal crônica em hemodiálise: descrição do tratamento e problemas enfrentados pelo paciente, sua família e equipe de saúde. [dissertação]. Ribeirão Preto (SP): Escola de Enfermagem de Ribeirão Preto/USP; 1981.

7. Cesarino CB, Casagrande LDR. Paciente com insuficiência renal crônica em tratamento hemodialítico: atividades educativas do enfermeiro. Rev Latino am Enfermagem 1998 out.; 6(4):31-40.

8. Silva LF, Guedes MVC, Moreira RP, Souza ACC. Doença crônica: o enfrentamento pela família. Acta Paul Enfermagem 2002; 15(1):40-7.

9. Ministério da Saúde (BR). Conselho Nacional de Saúde. Resolução n. 196, de 10 de outubro de 1996. Trata das diretrizes e normas regulamentadoras de pesquisas envolvendo seres humanos. Brasília; 1996. 18p.

10. Prado D. O que é família. $9^{a}$ ed. São Paulo: Brasiliense; 1989.

11. Carter B, McGoldrick M, organizadoras. As mudanças do ciclo de vida familiar: uma estrutura para a terapia familiar. Porto Alegre: Artes Médicas; 1995.

12. Marcon SS, Andrade OG, Silva DMP. Percepção de cuidadores familiares sobre o cuidado no domicílio. Texto Contexto Enf 1998 maio/agosto; 7(2):289-307.

13. Marcon SS, Waidman MAP, Carreira L, Decesaro MN. Compartilhando a situação de doença: o cotidiano de famílias de pacientes crônicos. In: Elsen I, Marcon SS, Silva MRS. O viver em família e sua interface com a saúde e a doença. Maringá: Eduem; 2002.

14. Marcon SS. Criar os filhos: experiências de famílias de três gerações. [tese]. Florianópolis (SC): Programa de Pósgraduação em Enfermagem/UFSC; 1998.

15. Budó MLD. Cuidando e sendo cuidado: um modelo cultural de saúde em comunidade rural de descendentes de italianos. [dissertação]. Santa Maria (RS): Pós Graduação em Extensão Rural/ UFSM; 1994.

16. Lima AFC: Gualda DMR. Reflexão sobre a qualidade de vida do cliente renal crônico submetido a hemodiálise. Nursing 2000 novembro; 3(30):20-3.

17. Riella MC. Insuficiência renal crônica. In: Riella MC. Princípios de nefrologia e distúrbios hidroeletrolíticos. Rio de Janeiro (RJ): Guanabara Koogan; 1996.

18. Gomes CMA. Descrição da qualidade de vida dos pacientes em hemodiálise. Rev Méd Minas Gerais 1997; 7(2/ 4):60-3.
19. Monteiro ARM, Barroso MGT . Trabalho $X$ doente mental: percepção da família. Rev Bras Enfermagem 1999 janeiro/ março; 52(1):118-28.

20. Barbosa JC, Aguillar OM, Boemer MR. O significado de conviver com a insuficiência renal crônica. Rev Bras Enfermagem 1999 abr./jun.; 52(2):293-302.

21. Pitta AMF. Qualidade de vida: uma utopia oportuna. Ciência \& Saúde Coletiva 2000; 5(1):24-7. 